Arteterapia. Papeles de arteterapia y educación para inclusión social ISSN-e 1988-8309

http://dx.doi.org/10.5209/ARTE.59763

\title{
Propuesta de un modelo teórico de intervención en arteterapia familiar. El proceso creativo como herramienta terapéutica en el trabajo con familias
}

\author{
Estibaliz Gutierrez Ajamil ${ }^{1}$ - Iñigo Ochoa de Alda Martínez de Apellaniz²
}

Recibido: 3 de abril de 2018/ Aceptado: 23 de junio de 2018

Resumen. Tras la revisión de los referentes teóricos que existen para el abordaje arteterapéutico con familias, este trabajo parte de una investigación en la que se han analizado los resultados de 3 años de trabajo de campo en esta área, logrando identificar diferentes elementos de la intervención clínica y del setting en Arteterapia Familiar. El objetivo del presente trabajo es ofrecer una propuesta teórica acerca de los aspectos contratrasferenciales y vinculares en el trabajo arteterapéutico y sus implicaciones en la intervención familiar. Para lograr dicho objetivo se han integrado dos paradigmas: el vínculo triangular arteterapéutico con una perspectiva psicodinámica y las relaciones familiares desde los fundamentos de la terapia sistémica. En lo referente a la intervención con familias, se ha diseñado un modelo teórico que permite adaptar los objetivos terapéuticos a las necesidades específicas de cada caso. Esta propuesta metodológica tiene como finalidad principal que los miembros puedan explorar nuevos sistemas de relación y de colaboración más funcionales a través del proceso creativo compartido, además de desarrollar su expresión emocional utilizando el lenguaje visual como una vía de comunicación intrafamiliar.

Palabras Clave: Arteterapia; Terapia Familiar; Proceso Creativo; Arteterapia Familiar.

[en] Proposal for a theoretical intervention model in family art therapy. The creative process as a therapeutic tool when working with families.

\footnotetext{
Abstract. In view of the current theoretical references to using art therapy with families, this work is based on a research analysing the results of three years of fieldwork in this area, identifying different elements of clinical intervention and setting in Family Art Therapy. The aim is to make a theoretical proposal on the countertransference and relationship aspects of art therapy work and their implications for family intervention. Two paradigms have been integrated to achieve this aim: the art therapy triangular bonding from a psychodynamic perspective and family relations according to the foundations of systemic therapy. For family interventions a theoretical model has been designed that enables the adapting of therapeutic goals to the specific needs of each case. The main aim of this methodological proposal is that family members use a shared creative process to explore new, more functional relationship and collaboration systems and additionally develop their emotional expression using visual language as a means of intra-family communication.

Keywords: Art Therapy; Family Therapy; Creative Process; Family Art Therapy.

1 Instituto MAP (Música, Arte y Proceso)- Centro Terapéutico. Dra. en Bellas Artes (UPV-EHU). Máster en Arteterapia y Educación Artística para la Inclusión Social (UVa). Arteterapeuta y docente en Instituto MAP (Música, Arte y Proceso) de Vitoria-Gasteiz

estibaliz@agruparte.com

2 Universidad del País Vasco- Euskal Herriko Unibertsitatea. Dr. en Psicología. Psicólogo clínico y psicoterapeuta familiar. Profesor del Departamento Personalidad, Evaluación y Tratamientos Psicológicos de la Facultad de Psicología (UPV-EHU) inigo.ochoadealda@ehu.eus
} 
Sumario. Introducción, Contextualización del arteterapia familiar, Integración de modelos teóricos para la intervención arteterapéutica con familias, Propuesta de un modelo teórico de intervención, Otros resultados de investigación, Conclusiones.

Cómo citar: Gutierrez Ajamil, E., Ochoa de Alda, I. (2018). Propuesta de un modelo teórico de intervención en arteterapia familiar. El proceso creativo como herramienta terapéutica en el trabajo con familias, en Arteterapia. Papeles de arteterapia y educación para inclusión social 13, 2018, 33-52.

\section{Introducción}

El arteterapia, siendo una profesión relativamente reciente, necesita continuar desarrollando un marco teórico propio basado en la práctica clínica que nos permita generar fundamentaciones conceptuales propias para esta disciplina. La propuesta metodológica que se expone a continuación nace de una investigación doctoral, Arteterapia con Familias de Niños con Cáncer. Dinámica Familiar en la Creación Plástica, defendida en 2017, en la que se ha trabajado con un total de 10 familias (36 personas), llevando a cabo una media de 17 sesiones por familia (Gutiérrez, 2018). Dado que se partía de un planteamiento experimental sobre un programa de arteterapia familiar, se optó por utilizar como metodología de investigación la Teoría Fundamentada, que conlleva un sistema de análisis exhaustivo del trabajo de campo, para posteriormente conceptualizar los datos obtenidos y finalmente inferir un planteamiento teórico.

En este artículo se aborda uno de los resultados de dicha investigación: la fundamentación teórica acerca de los elementos contratransferenciales y vinculares en arteterapia familiar. Con el objetivo de proponer un modelo de intervención que pueda ser adaptable a diferentes tipologías familiares, poblaciones y demandas, se ha profundizado en la instrumentalización del proceso creativo como recurso para el trabajo terapéutico. Los conceptos teóricos inferidos se han representado a partir de esquemas gráficos que permiten comprender visualmente los vínculos y dinámicas que se ponen en juego durante las sesiones familiares. Para poder comprender la aportación de este modelo teórico se ha realizado una breve contextualización y recorrido histórico del arteterapia familiar hasta la actualidad, basándonos en conceptos arteterapéuticos, psicodinámicos y sistémicos, para posteriormente poder integrar dichas orientaciones en una misma propuesta teórica. Finalmente se ejemplifican tres estrategias de intervención que permiten trabajar los objetivos terapéuticos usando la creación plástica como vía de comunicación intrafamiliar.

\section{Contextualización del arteterapia familiar}

En los últimos años se observa un creciente interés por los procesos creativos compartidos entre padres-madres e hijos/as y se ha hecho patente la necesidad de profundizar en la teorización del trabajo arteterapéutico con familias (Hervás, 2016). Esta modalidad de intervención implica una serie de especificidades que difieren de las sesiones individuales o grupales, ya que cada familia cuenta con su propia organización, estilo comunicativo, dinámica relacional e historia compartida por los miembros, elementos que condicionarán tanto el desarrollo de la sesión como la evolución del funcionamiento familiar lo largo del proceso terapéutico. 
Tras realizar una revisión bibliográfica sobre arteterapia familiar se observa que la mayor parte de las referencias publicadas consisten en estudios de casos realizados en EEUU, que han ido permitiendo desarrollar algunos planteamientos teóricos y diseñar propuestas de intervención para este ámbito. En la actualidad comienzan a registrarse algunos resultados de intervenciones en arteterapia familiar con metodologías de investigación, lo que está permitiendo conocer y fundamentar el potencial de la expresión plástica en procesos de terapéuticos con familias (Moghaddam et al., 2016; Moore, 2005; Im et al, 2010).

La intervención en Arteterapia Familiar nace de la integración de los fundamentos del Arteterapia y de la teoría de la Terapia Familiar Sistémica. La terapia sistémica tiene su origen en EEUU a mediados del siglo XX y durante las siguientes décadas sus precursores centraron sus investigaciones en desarrollar conceptos teóricos aplicables a la práctica clínica. En cambio, el origen del Arteterapia Familiar resulta más difuso, ya que paralelamente varios terapeutas comenzaron a utilizar técnicas plásticas en el trabajo clínico con parejas y familias. Hoshino (2008) concluye que escasez de bibliografía sobre la intervención arteterapéutica con familias proviene de la necesidad que sintieron aquellos profesionales de buscar soluciones prácticas en su trabajo clínico, sin enfocar los resultados hacia una fundamentación teórica generalizable.

Las pioneras del arteterapia familiar observaron el potencial que la creación plástica podía aportar a los procesos de terapia familiar, por lo que en diferentes clínicas estadounidenses comenzaron a realizarse simultáneamente colaboraciones entre arteterapeutas y terapeutas familiares. Las primeras incursiones del arteterapia dentro de tratamientos familiares consistieron en su mayoría en sesiones puntuales en las que un/a arteterapeuta ofrecía una serie de propuestas creativas a las familias mediante consignas directivas, con el fin de poder observar aspectos relacionales que ofreciesen una mayor información al psicoterapeuta familiar que iba a realizar el tratamiento posterior. A través de estas colaboraciones, fueron varias las arteterapeutas que se formaron en terapia familiar con el objetivo de poder intervenir con las familias desde una orientación sistémica. Entre estas profesionales se encuentra Hanna Kwiatkowska, considerada la precursora del Arteterapia Familiar. Kwiatkowska inició sus estudios en arteterapia con Margaret Naumburg y en los años 70 trabajó en el National Institute of Mental Health (NIMH), introduciendo elementos arteterapéuticos en los tratamientos de terapia familiar. A partir de su trabajo otras arteterapeutas como Judy Rubin, Harriet Wadeson, Helen Landgarten, Cathy A. Malchiodi, Maxine Borowsky Junge, Shirley Riley, Doris Arrington o Debra Linesch han continuado desarrollando a finales del siglo XX diferentes técnicas arteterapéuticas para el trabajo clínico con familias y parejas.

A pesar de la diversidad de estrategias, herramientas, técnicas y poblaciones sobre las que han trabajado estas autoras, se advierten algunos elementos comunes en sus reflexiones sobre la utilidad del arteterapia familiar. Los terapeutas familiares comenzaron a colaborar con arteterapeutas en las sesiones iniciales al constatar que a través del proceso creativo de la familia podía observarse la dinámica y los roles de sus miembros, resultando un método poco invasivo para los pacientes. Hoshino (2008) añade que habitualmente las parejas y las familias llegan a consulta con un discurso aprendido y repetido, con una narrativa organizada sobre sus problemas y sus necesidades, y resulta muy útil introducir el proceso creativo en estos casos, ya que en arteterapia el lenguaje verbal queda en un segundo plano. Riley y Malchiodi 
(2003) también explican que el arteterapia familiar ayuda a que todas las generaciones sean igualmente escuchadas a través de la expresión plástica, y señalan algunos beneficios que el proceso creativo aporta a la intervención sistémica, como la construcción de metáforas, la reformulación de relaciones doble vinculares, la detección de patrones reiterativos y la capacidad de desarrollar cambios adaptativos a las variaciones que se den en el entorno.

\section{Integración de modelos teóricos para la intervención arteterapéutica con familias}

Tras la investigación Arteterapia con Familias de Niños con Cáncer, ha sido posible conceptualizar algunos de los factores que influyen en este tipo de procesos arteterapéuticos, convergiendo el paradigma de la terapia sistémica junto con una visión psicodinámica del proceso creativo. Para ello se parte de una propuesta de trabajo no directiva, en la que se favorece el trabajo experiencial con los materiales sin una consigna concreta en cuanto al motivo de creación. Este sistema de trabajo ha permitido que las familias exterioricen aspectos conscientes e inconscientes de su dinámica habitual, permitiéndonos detectar y comprender desde un marco teórico los procesos vinculares que ocurren dentro de la sesión entre los miembros, con el arteterapeuta y con la producción plástica.

\subsection{Vínculo triangular arteterapéutico}

En 1990, las arteterapeutas Wood, Case y Schaverien ofrecieron una conferencia en Manchester titulada "Triangular relationship", en la que proponían un modelo teórico propio del arteterapia con el que tratar de definir los límites de la práctica clínica de la disciplina. El vínculo triangular que enmarca los procesos arteterapéuticos interrelaciona tres elementos indispensables: obra/producción plástica $(\mathrm{O})$, paciente/ cliente (P) y arteterapeuta (AT), originalmente denominados image-client- therapist. La representación gráfica del vínculo entre estos tres elementos hace referencia a las especificidades de los fenómenos contratransferenciales en arteterapia, desde una perspectiva psicodinámica (analytical art psichotherapy) (Véase figura1).

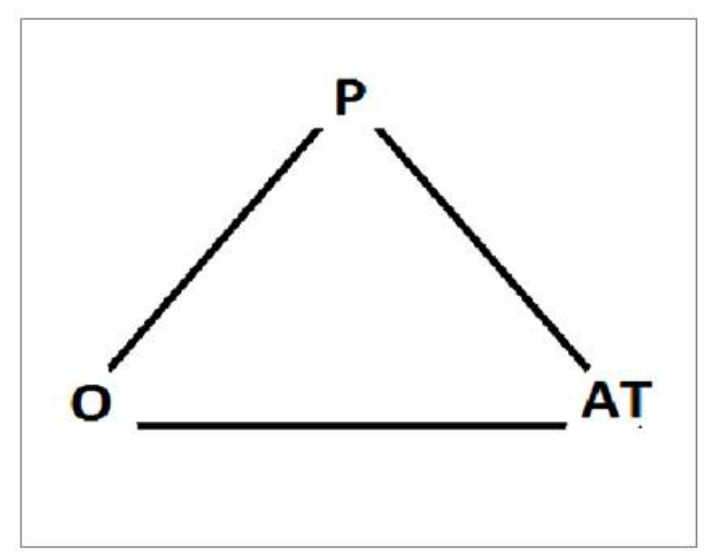

Figura1. Vínculo triangular arteterapéutico. 
El psicoanálisis entiende por transferencia los procesos inconscientes mediante los que el paciente actualiza en la relación con el terapeuta una repetición de prototipos vinculares infantiles (Laplanche, J y Pontalis J.B., 2001). Al mismo tiempo en la relación terapéutica surge la contratransferencia, que Corveleyn (1997) define como "sentimientos y representaciones conscientes e inconscientes que son despertadas en el analista al escuchar al paciente" (p. 159). En la práctica psicodinámica los procesos transferenciales resultan material clínico dentro de la terapia, y su conceptualización y manejo ha ido evolucionando junto con el desarrollo del psicoanálisis. Las primeras teorías freudianas identificaban la contratransferencia como sentimientos del terapeuta que debían ser dominados e incluso evitados, de modo que el analista cumpliese un rol de "espejo" del paciente (Goldschmidt. 2010). Ante esta rigidez en los roles, surgieron nuevas orientaciones que comprenden los procesos transferenciales como un fenómeno natural de la relación terapéutica, resultando indispensable que el profesional sea capaz de identificar y manejar los elementos contratransferenciales que se dan en sesión a través del trabajo de análisis y supervisión externa.

Además del vínculo interpersonal que se establece entre el paciente y el terapeuta, en el trabajo arteterapéutico existe un tercer elemento que influye en dicha relación: la producción plástica (o la obra) resultante del proceso creativo en las sesiones. La alianza terapéutica no solo se basa en la escucha, sino que la observación cumple una función prioritaria, permitiendo un juego de miradas en el que el paciente y el terapeuta comunican y se comprenden. En esta relación tríadica paciente-obra-terapeuta los fenómenos contratransferenciales se vuelven más complejos, ya que el vínculo terapéutico incluye la subjetividad implícita del arteterapeuta y del paciente sobre la imagen. La obra cumple la función de objeto mediador entre ambos, dando lugar a lo que Schaverien (2000) denominó contratransferencia estética (aesthetic countertransference).

Aunque tradicionalmente en arteterapia se ha otorgado un mayor valor a lo que ocurre durante el proceso creativo en sesión que a la producción plástica resultante, Schaverien (2000) matiza que la observación de la imagen por parte del arteterapeuta también se encuentra condicionada a nivel contratransferencial, por lo que resulta importante dentro del proceso terapéutico que el profesional sea consciente de la apreciación estética que está haciendo sobre la obra del paciente. El vínculo triangular en arteterapia favorece fenómenos transferenciales en los la obra plástica también es receptora y emisora de mensajes, lo que permite una visión más amplia del paciente, quien muestra su "mundo externo" en la relación transferencial con el terapeuta, y al mismo tiempo puede plasmar aspectos de su "mundo interno" a través del lenguaje visual. Del mismo modo, en la contratransferencia, el paciente recibe dos devoluciones simultáneas: la interpersonal por parte del terapeuta, y la de su expresión interna convertida en un objeto tangible, en la relación paciente-obra.

Schaverien (2000), en su planteamiento sobre el vínculo triangular, explica que la función del arteterapeuta durante el proceso creativo del paciente se basa en dar sentido a los fenómenos transferenciales que están ocurriendo, ofreciendo un espacio seguro y contenedor en el que estos puedan tener lugar. En la contratransferencia, el objetivo del profesional consiste en comprender y dar valor al discurso visual del paciente, permitiéndole explorar nuevas vías de comunicación. Este modelo arteterapéutico está orientado hacia una intervención individual, pero ¿qué ocurre cuando en sesión nos encontramos con una familia, en la que los miembros ya tienen sus propios vínculos entre sí? ¿De qué manera afecta la contratransferencia estética en la dinámica intrafamiliar? Para poder identificar esta serie de fenómenos, nos hemos centrado en algunos conceptos sistémicos sobre las relaciones familiares. 


\subsection{Fundamentos de la teoría sistémica (escuela Estructural)}

Como hemos visto desde la perspectiva del vínculo triangular, es imprescindible la comprensión de los diferentes elementos transferenciales, ya que en la sesión se ponen en juego no solo relaciones interpersonales, sino también vínculos con el objeto material o producción plástica. Una vez comprendida la función del arteterapeuta como representante del espacio seguro y contenedor, así como la utilidad de la obra, no con un fin interpretativo sino como objeto mediador en la contratransferencia, a continuación nos centramos en el último vértice del triángulo, el paciente, en este caso entendido desde un prisma de "sistema familiar". Para ello, consideramos útil la fundamentación de la Terapia Familiar Sistémica, que resalta la importancia de la interacción entre los diferentes miembros del sistema familiar y de éste con su entorno social para poder comprender los problemas individuales. Esta epistemología es la base de múltiples escuelas que se diferencian en la aplicación de técnicas, objetivos, encuadre, etc., centrándonos en Arteterapia Familiar Estructural para el planteamiento de intervención aquí propuesto.

La escuela Estructural se interesa especialmente por los aspectos estructurales y organizativos de la familia. Según Minuchin (1979), la familia es entendida como un sistema abierto en interacción con el medio social, encontrándose en una fase del ciclo vital concreta, en el que deben desarrollarse una serie de funciones específicas que faciliten la adaptación del sistema a dicha etapa. Una familia que sufre, es una familia en la que esta adaptación no se está pudiendo desarrollar de una manera adecuada por algún tipo de estresor. La forma de afrontar por parte de la familia este estresor lleva a una serie de pautas transaccionales disfuncionales (serie de interacciones rígidas) en el sistema que lejos de facilitar el bienestar emocional de los miembros del sistema, provoca dolor. De tal modo que observar las interacciones familiares sería clave para valorar la disfunción del sistema y poder proponer relaciones alternativas que desarrollen y potencien recursos más sanos en el sistema familiar.

La estructura hace referencia al conjunto de elementos que organizan las diferentes relaciones entre los miembros de la familia (Minuchin. 1979), estando condicionada por tres dimensiones estructurales que nos indican la salud o patogenicidad del funcionamiento familiar: los límites, que definen los miembros que participan o se excluyen de una acción y concretan los roles que adoptarán cada uno; la alineación, que recoge la unión u oposición entre los miembros (coalición cuando dos miembros se unen contra un tercero y alianza si dos miembros se unen excluyendo a los demás) y el poder, que consiste en la energía que activa al sistema para promover sus acciones.

Minuchin (1979) señala que la estructura familiar se compone por tres diferentes subsistemas principales: el subsistema conyugal, que se basa en la complementariedad y en la alianza de la pareja, no debiéndose confundir con el parental; el subsistema parental, que surge con el nacimiento del/la primer/a hijo/a, y sirve para ayudar al/la niño/a en su crianza y socialización y el subsistema fraternal, que está compuesto por los/as hijos/as de la familia y ofrece un espacio para la experimentación de las relaciones con los iguales.

Otro de los aspectos estructurales a analizar en terapia es la jerarquía, es decir, las normas y patrones de interacción que diferencian el grado de poder y de toma de decisiones. La arteterapeuta Hoshino (2008) señala que los retratos familiares que se producen en las sesiones de arteterapia familiar ofrecen información acerca de cómo los miembros viven la dinámica familiar, expresando de forma inconsciente las jerarquías, alianzas y poder, al observar dónde dibujan a cada miembro, de qué tamaño y en qué orden. 
El setting de la escuela estructural resulta versátil ya que adapta algunos parámetros de su encuadre como la temporalización del tratamiento y la frecuencia de las sesiones a las necesidades de la familia. Generalmente el proceso terapéutico suele consistir en reunir en el mismo espacio y al mismo tiempo a todos los miembros a los que les afecta el problema a trabajar. Dependiendo del tipo de disfunción familiar o de los objetivos del terapeuta, también es posible trabajar en diferentes sesiones con los subsistemas familiares por separado. La teoría sistémica defiende que no es posible trabajar en terapia con un sistema de forma aséptica y neutral, ya que al formar parte del proceso terapéutico de la familia, toda percepción del profesional resulta autorreferencial (Keeney, B. y Ross, J, 1987). Por lo que el rol del terapeuta es el de provocar y guiar el cambio, utilizando dos características complementarias: la espontaneidad y la planificación.

En el planteamiento que se propone en este trabajo hemos utilizado un instrumento gráfico que diseñó la escuela Estructural para poder recoger información compleja sobre la organización de la familia de una forma visual. Se denomina mapa familiar, y en él se plasman el número de miembros, los subsistemas, la jerarquía, las relaciones, los límites y las alineaciones, lo que permite hacer hipótesis sobre los roles familiares y la función del síntoma en la dinámica familiar. A la hora de realizar el mapa familiar resulta necesario observar los patrones relacionales entre los miembros para identificar las dimensiones que inciden en la organización estructural, y así poder focalizar en las necesidades o dificultades de los miembros y valorar la posibilidad de elaborarlas en las sesiones de arteterapia.

Para el desarrollo de este modelo teórico se ha optado por utilizar como ejemplo un mapa familiar excesivamente organizado que permite comprender las dimensiones a tener en cuenta por el arteterapeuta en la fase de observación (Véase figura 2). En dicho mapa se ejemplifica un núcleo familiar de cuatro miembros, con parentalidad diádica y en la que la figura paterna (P) y la figura materna (M) se encuentran al mismo nivel jerárquico, al igual que en el caso del subsistema fraternal, compuesto por el hijo mayor (H1) y el hijo menor (H2). La línea discontinúa representa unos límites claros pero permeables entre el subsistema parental y filial. No se han incluido ninguna simbología sobre las alineaciones con la intención de simplificar el mapa.

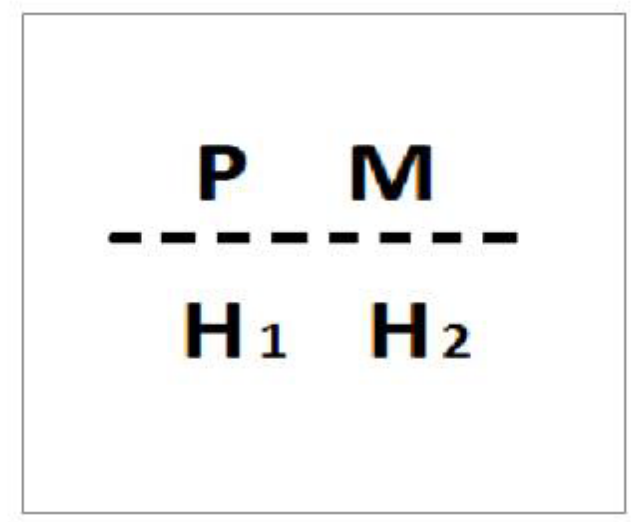

Figura 2. Mapa familiar (escuela Estructural) 


\subsection{El vínculo arteterapéutico con familias}

Como se ha señalado anteriormente, en las sesiones de arteterapia se ponen en juego las pautas transaccionales habituales del sistema a través del proceso de creación compartido por los miembros, ofreciendo al terapeuta la oportunidad de observar in situ la dinámica familiar, las dificultades y la capacidad de adaptación de los miembros ante los estresores externos. En este tipo de intervención el vínculo tríadico Paciente/Obra/Arteterapeuta se amplía, ya que en este caso es necesario sustituir la figura del paciente $(\mathrm{P})$ por el núcleo familiar $(\mathrm{F})$, con sus propias dinámicas relacionales y vínculos entre los miembros (Véase figura 3.1). Es decir, en las sesiones familiares los miembros establecen una relación vincular con el arteterapeuta y la obra, en función de su situación personal, su bagaje personal y su historia familiar.

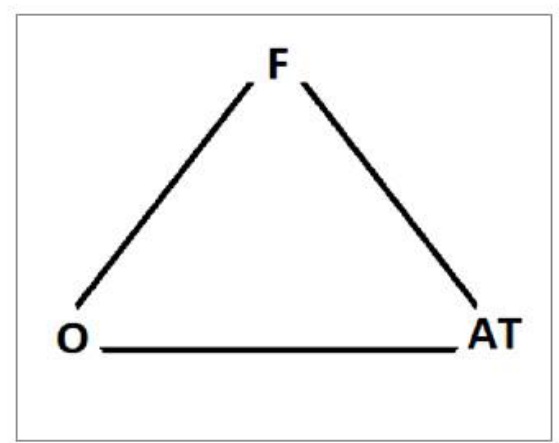

3.1. Relación triádica Familia/Obra/Arteterapéuta

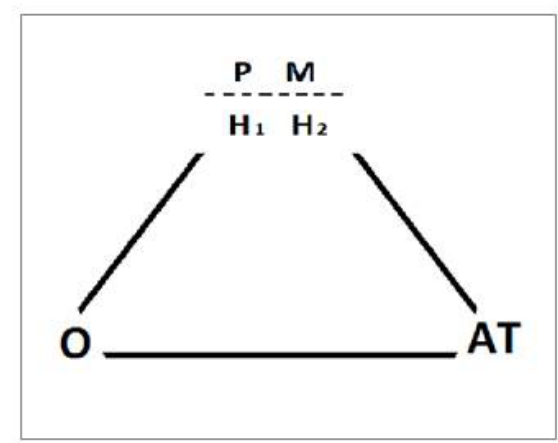

3.2. Estructura familiar en el proceso creativo

Figura 3. Vínculo arteterapéutico con familias.

Para poder recoger el funcionamiento del sistema familiar durante el proceso creativo se ha diseñado una versión del vínculo arteterapéutico en el que se integra el mapa familiar de la escuela Estructural (Véase figura 3.2). Antes de comenzar las sesiones, conviene realizar una primera entrevista verbal en la que poder definir la demanda, siendo útil para ello recoger el genograma de la familia, así como su visión de los miembros sobre la situación familiar, el origen de las dificultades y las necesidades actuales. Posteriormente, para trazar el mapa de cada familia, es necesario llevar a cabo unas sesiones iniciales de exploración en las que el arteterapeuta cumple las funciones de observación y acompañamiento de la familia durante el proceso creativo. En estas primeras sesiones se va construyendo el sistema terapeútico, un espacio de colaboración mutua en el que el terapeuta no cuestiona la organización familiar, sino que facilita las interacciones habituales del sistema.

De la misma forma que en los procesos de psicoterapia familiar, en esta fase inicial el arteterapeuta a través de la observación va infiriendo los tipos de relaciones predominantes en cada sistema familiar, los límites, la jerarquía, las alianzas o coaliciones, el tipo de roles, etc. Además, al utilizar el desarrollo del proceso creativo como elemento de análisis del funcionamiento familiar, se favorece que los miem- 
bros se comuniquen a través de tres lenguajes simultáneamente: el lenguaje verbal, el no verbal y el lenguaje visual. Ello permite que la familia, y en especial los niños, puedan interactuar y mostrarse de forma espontánea a través del juego y de la exploración de los materiales.

La observación de la dinámica familiar en torno al proceso creativo ayuda a detectar las pautas transaccionales disfuncionales en torno al síntoma y a la demanda, pudiendo establecer unos objetivos y elaborar un plan de trabajo específico para cada caso. Al mismo tiempo, en esta primera fase el arteterapeuta debe acomodarse al estilo comunicativo de la familia para favorecer la gestación de la alianza, y es en este proceso cuando se consolida el sistema terapéutico (Minuchin y Fishman, 1984) como resultado de la integración del sistema del arteterapeuta y el del sistema familiar. La alianza terapéutica facilitará que los miembros sean más permeables a las intervenciones de una posterior fase, en la que el arteterapéuta deberá proponer pautas alternativas más funcionales a través del proceso creativo.

\section{Propuesta de un modelo teórico de intervención}

Tras las primeras sesiones de exploración con el sistema familiar, se construye un mapa relacional en el que se representen las pautas transaccionales más disfuncionales, dando paso a la fase de intervención. Para llevar a cabo nuestra propuesta se debe establecer el contrato terapéutico con la familia, definiendo el setting, la estructuración y los objetivos de intervención sobre los que se trabajará específicamente con cada caso.

Como encuadre general, proponemos llevar a cabo un proceso terapéutico con todo el núcleo familiar en sesiones semanales de una hora, y partiendo de los resultados de investigación, se observa la conveniencia de realizar un mínimo de 11-13 sesiones para poder abordar los objetivos de intervención. En cuanto a la metodología, generalmente la bibliografía sobre arteterapia familiar muestra estudios de caso en los que el arteterapeuta ofrece consignas y propuestas dirigidas hacia un tema en función del proceso psicoterapéutico, dando lugar a imágenes que permitan hablar a las familias sobre sus conflictos. En el caso de Arteterapia con Familias de Niños con Cáncer se optó por ofrecer sesiones bajo una metodología menos directiva, en la que la arteterapeuta propone materiales y técnicas plásticas concretas en función de los objetivos terapéuticos, dejando libertad a los miembros para la elección de los motivos pictóricos. Como resultado, se observa que interactuar libremente con los materiales permite a la familia llevar a cabo un proceso creativo espontáneo, así como generar un lenguaje simbólico propio sobre sus propias necesidades expresivas, emocionales y vinculares (Gutiérrez, 2018).

El objetivo común en arteterapia familiar consiste en que los miembros puedan experimentar de forma práctica nuevos sistemas de relación, de comunicación y de colaboración. Para ello en arteterapia contamos con el potencial de la creación, que permite plantear retos y desarrollar alternativas de una forma activa durante la sesión. En este sentido, la función del arteterapeuta consistirá en favorecer experiencias de creación compartida que ayuden a la familia a buscar nuevas estrategias en lugar de repetir las pautas transaccionales disfuncionales. Para ello, proponemos un sistema de trabajo que intercale procesos creativos simultáneos, familiares y diádicos que ayuden en la consecución de los objetivos terapéuticos. 


\subsection{Proceso creativo simultáneo}

El trabajo simultáneo o individual en las sesiones familiares implica que cada uno de los miembros se enfrente a su propio proceso creativo. Por un lado, este modelo de trabajo permite experimentar fenómenos transferenciales similares a los procesos terapéuticos descritos por Schaverien, en las que se establece un vínculo entre la obra, su autor y el arteterapeuta (Véase figura 4).

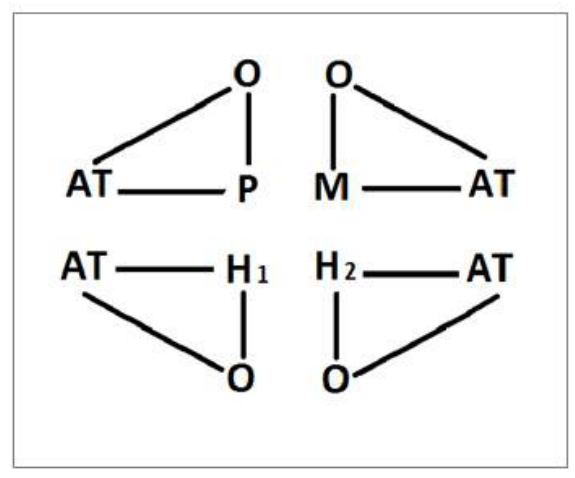

Figura 4. Proceso creativo individual.

Por otro lado, el desarrollo de varios procesos creativos simultáneos por parte de la familia provoca que cada persona pueda observar cómo los otros miembros dan diferentes respuestas a una misma propuesta o técnica artística, tomando conciencia de las alternativas que se pueden generar dentro del núcleo familiar ante un mismo problema o reto. Es decir, que el juego de miradas que se da a través del vínculo triangular en este caso se multiplica, favoreciendo que los miembros se muestren y se observen entre sí, tanto en la expresión de su "mundo interno" a través de la imagen como de su "mundo externo" o interpersonal.

Donelly (2000) explica que generalmente las precursoras del arteterapia familiar llevaban a cabo sesiones en las que todos los miembros crean una producción de forma conjunta, y matiza que en ocasiones favorecer procesos creativos simultáneos en todos los miembros permite visibilizar conflictos que habitualmente se obvian o se evitan en la dinámica familiar. En estos casos el proceso creativo individual y la puesta en común de las obras producidas en sesión ayudan a dar valor cada uno de los miembros, así como a su proceso, a sus ideas, necesidades y perspectivas del funcionamiento familiar. Como señala Deco (1990), en las sesiones familiares de trabajo simultáneo las obras no cumplen tanto una función de insight y exploración personal, sino que las imágenes producidas por los miembros son una vía de comunicación dentro del sistema familiar.

Desde un plano contratransferencial, es necesario tener en cuenta que la intervención del arteterapeuta condicionará la relación de cada miembro con su producción plástica, así como con el resto de su familia. Aunque una de las funciones principales del arteterapeuta consista en acompañar al autor en la reflexión del lenguaje simbólico de su producción, cuando en las sesiones familiares se trabaja través del proceso 
creativo simultáneo el diálogo sobre la imagen debe ser especialmente cuidado, ya que es habitual que una o varias personas de forma inconsciente proyecten aspectos de sí mismos en la obra, pero que no deseen compartirlos con otros miembros de la familia. Si bien es cierto que el arteterapeuta puede conformar hipótesis sobre los mensajes que posiblemente los miembros estén transmitiendo a través del lenguaje visual, se debe priorizar la gestación de una alianza terapéutica en la que todos los miembros sientan respetados sus ritmos, mecanismos defensivos y resistencias. Uno de los riesgos de la terapia familiar es la dispersión de los límites individuales, por lo que es vital hacer sentir que cada miembro pertenece a la familia, pero también tiene conflictos o dificultades individuales y necesidad de autonomía. Por ese motivo, uno de los principales objetivos del arteterapeuta en el proceso creativo simultáneo consiste en favorecer un espacio seguro y estable en el que cada miembro pueda desarrollar estrategias personales de creación. El arteterapeuta debe dar sentido a lo que ocurra durante el proceso creativo, promoviendo la comunicación intrafamiliar, pero respetando la necesidad o la negativa de cada persona a la hora de exponerse ante los otros miembros mediante el discurso visual y verbal. En este espacio compartido por la familia, donde se da lugar a imágenes y procesos creativos individuales, el rol del arteterapeuta implica decidir a quién dirigirse, cómo dirigirse y para qué dirigirse, comenzado a darse la danza terapéutica (Whitaker y Bumberry, 1998) donde cada paso es clave para el siguiente.

\subsection{Proceso creativo conjunto}

El trabajo conjunto consiste en que todos los miembros desarrollen su proceso creativo sobre un mismo soporte, o realicen una sola producción entre todos (Véase figura 3.2). Ello conlleva que los miembros deban tomar decisiones, llegar a acuerdos, confrontar ideas o propuestas con otros miembros, aceptar las diferencias entre sí, y en definitiva, desarrollar dinámicas de colaboración para llegar a un resultado común, tratando de lograr resultados plásticos con los que todos los miembros se sientan identificados.

A lo largo del proceso creativo conjunto se generan momentos de conflicto, de negociación y de cooperación entre los miembros, en los que surgen los movimientos homeostáticos (mecanismos reguladores del sistema que oponen resistencia al cambio con el objetivo de que la estructura familiar no se altere) o bien se den $\mathrm{mo}$ vimientos morfogenéticos (mecanismos adaptativos ante las crisis, que permiten a la familia incorporar nuevos aspectos para evolucionar hacia un nuevo equilibrio en la estructura del sistema). La salud de la familia se irá observando en el proceso creativo conjunto, según la adaptabilidad frente a las nuevas situaciones que puedan surgir. La mediación de un profesional externo y unos objetivos terapéuticos concretos posibilitan que la familia experimente nuevos sistemas de comunicación, de roles y relaciones durante el propio proceso de creación, ayudándoles a los miembros a reflexionar sobre la naturaleza de sus relaciones en un entorno contenedor y distendido.

En el caso de las familias con niños, es habitual que en una primera fase los adultos deleguen la toma de decisiones respecto al motivo, materiales o reparto del trabajo en uno de los hijos, debido a la diferencia de actitudes entre adultos y niños frente al juego creativo y la exploración de los materiales. Si se da esta situación, el arteterapeuta puede integrar la función de ese niño o niña como parte de la interven- 
ción terapéutica, dando valor al rol de "auxiliar" del proceso creativo de sus padres. En estos casos resulta necesario constatar que dicha delegación inicial no se ejerce de forma rígida, ya que de lo contrario, se estaría dando una doble jerarquía (Madanes, 1984), donde uno de los hijos estaría cargando con la responsabilidad de liderar el proceso familiar, a pesar de que por su edad estaría debajo en la escala de poder. En este caso, el trabajo en arteterapia familiar consistiría en ayudar a los miembros a tomar conciencia de sus pautas transaccionales durante el propio proceso creativo. En etapas posteriores se tratará de generar un mayor equilibrio en la toma de decisiones, promoviendo que cada uno de los miembros se exprese, proponga ideas y sea escuchado, con el fin de lograr un una jerarquía congruente durante la creación.

Para poder desarrollar un lenguaje visual en el que la familia elabore elementos simbólicos propios (empowered images), resulta necesario un espacio temporal prolongado en el que se alternen sesiones con procesos creativos individuales y procesos creativos conjuntos. A medida que cada individuo logra expresar aspectos de sí mismo a través de la imagen, el discurso visual del sistema también se va enriqueciendo de recursos pictóricos que todos los miembros asumen como propios, generando una mayor pertenencia familiar (Gutiérrez, 2018). En este proceso, la contratranferencia estética se genera al observar la obra producida por la familia a partir del principio sistémico de totalidad (Watzlawick, Beavin y Jackson, 1983), por el cual el sistema se entiende como una unidad que transciende la suma de las partes. Es decir, que es función del arteterapeuta dar sentido al lenguaje simbólico común con el que se identifican los miembros, entendiéndolo como el resultado tangible de la dinámica familiar.

En este proceso creativo familiar, es de vital importancia observar las secuencias espontáneas de la familia, quién lidera el proceso, cómo se establece el reparto del trabajo, quién facilita, entre quiénes consensuan, quién pide ayuda, si algún miembro queda excluido o relegado en la toma de decisiones, etc. Por lo tanto, el proceso creativo permitirá comprender esos lazos relacionales invisibles que unen (funcional o disfuncionalmente) a los diferentes miembros, que en su conjunto forman una danza propia y específica de ese sistema familiar. En este punto, el arteterapeuta podrá ya ir recabando información sobre los roles, límites, funciones, alianzas o coaliciones que, lejos de facilitar la adaptación de la familia, la enquistan sin lograr una óptima adecuación al momento vital en el que se encuentran. A lo largo del proceso arteterapéutico, el profesional mediará en el trabajo creativo conjunto, favoreciendo nuevas dinámicas que se verán proyectadas en las imágenes de familia y quedarán recogidas en forma de producciones plásticas.

\subsection{Proceso creativo diádico}

Como hemos visto, en ocasiones resulta necesario intervenir sobre la propia alineación familiar, con el objetivo de restablecer el lugar de cada miembro en la estructura familiar y lograr una jerarquía más congruente (Haley, 1985) Para ello resulta imprescindible detectar las alianzas naturales que se dan en las sesiones, y posteriormente proponer formar equipos de trabajo diádicos en las que generen estilos relacionales alternativos entre los miembros, reforzando el equilibrio entre subsistemas.

En el caso de familias de cuatro miembros, generalmente las alianzas establecidas en la familia provocan un tipo de trabajo diádico en el que de forma espontánea el padre trabaja con uno de los hijos (ej.P-H2) y la madre con el otro (ej. M-H1). 
La modalidad de proceso creativo diádico que se proponga para intervenir en estos casos puede responder a dos objetivos terapéuticos diferentes:

a) Favorecer unas alianzas inversas a las que se dan espontáneamente, es decir, invitar a realizar un trabajo conjunto entre P-H1 y M-H2. (Véase figura 5.1) A través de esta propuesta de trabajo el proceso creativo facilita un canal de comunicación más consistente entre quienes se daba una mayor distancia, enriqueciendo así los lazos afectivos. Este tipo de trabajo conjunto permite afianzar las nuevas estrategias relacionales en la familia, ofreciendo el lenguaje no verbal y el lenguaje visual como recursos expresivos en la vivencia compartida en diadas.

b) Reforzar los subsistemas propios de la familia, es decir, llevando a cabo un proceso creativo paralelo la pareja (M-P) y los hermanos (H1-H2) (Véase figura 5.2). Esta modalidad de trabajo facilita el encuentro conyugal (que puede encontrarse muy dañado por el reparto en las necesidades de los hijos), y por otro lado, el proceso creativo compartido entre hermanos fortalece las funciones fraterno-filiales, enriqueciendo así las funciones básicas de este subsistema.

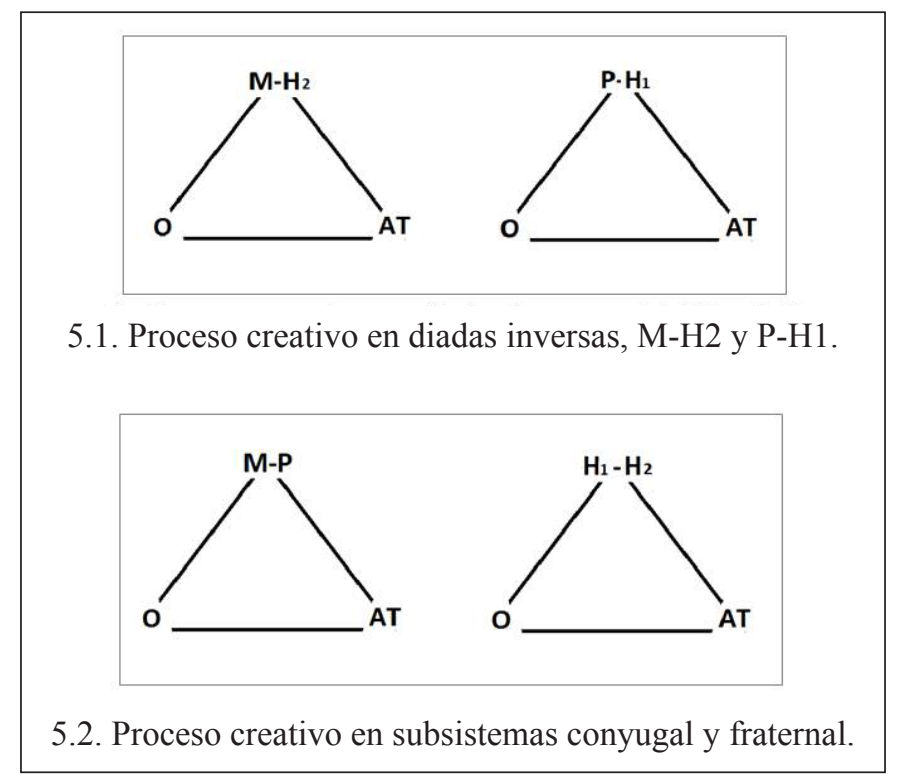

Figura 5. Proceso diádico con familias de cuatro miembros

Con las familias de 3 miembros (pareja con hijo/a único/a) la finalidad consiste en lograr una alineación en la que ambas figuras paternas se encuentren al mismo nivel de jerarquía respecto al hijo, tratando de reducir en la medida de lo posible las coaliciones intergeneracionales (cuando un hijo se encuenta metafóricamente sobre los hombros de uno de los padres, otorgándole un mayor poder respecto a la otra figura parental) entre los miembros. 
Con el objetivo de generar experiencias en la familia con una jerarquía congruente entre ambos padres, el arteterapeuta debe tratar de promover momentos a través del proceso creativo en el que el hijo trabaje de forma diádica con el progenitor con el que muestra más distancia, favoreciendo así un vínculo afectivo a través de la creación compartida entre ambos. Estas vivencias familiares con una dinámica alternativa a la habitual permiten reducir la distancia emocional marcada por la excesiva cercanía de la otra figura parental (Véase figura 6.1).

Otra vía de intervención sobre la alineación entre familias de tres miembros consiste en reforzar el subsistema conyugal, favoreciendo el trabajo conjunto de la pareja, y al mismo tiempo ayudando al niño a trabajar de forma independiente sobre sus propias creaciones. De esta forma, se hace explícita la necesidad de excluir al hijo de espacios parentales o conyugales, potenciando la autonomía del niño y por la tanto fortaleciendo la idea de los padres de la no necesidad de tener siempre presente al hijo en sus espacios diádicos) (Véase figura 6.2).

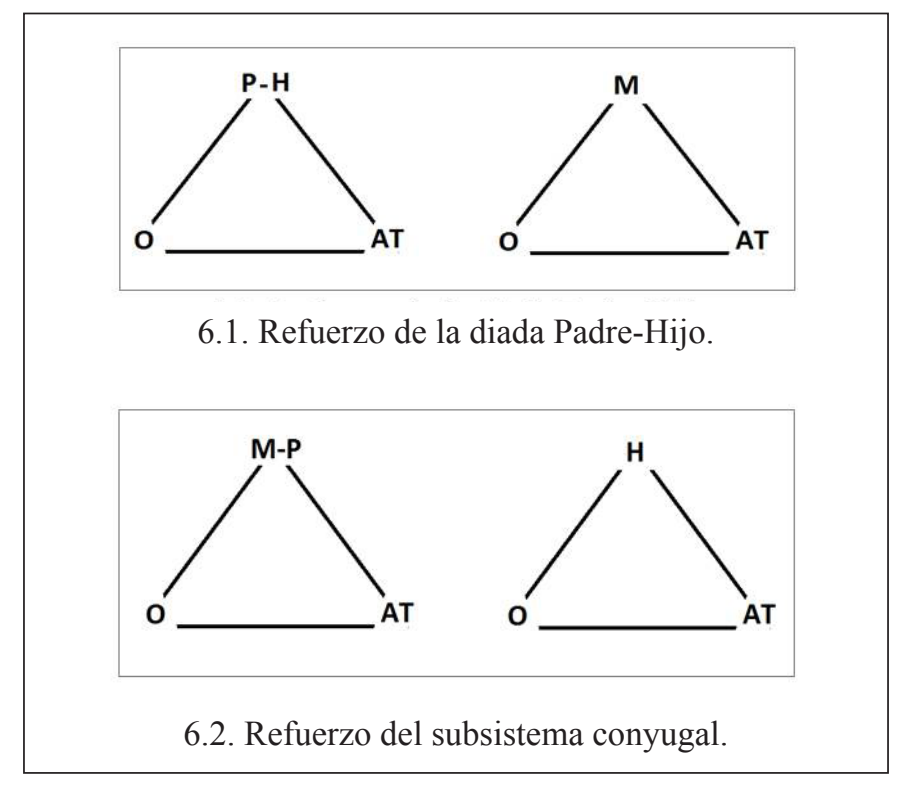

Figura 6. Proceso creativo diádico con familias de tres miembros.

En cualquier caso, el trabajo creativo en diadas siempre implica unas pautas transaccionales que no se dan de forma natural, sino que es el arteterapeuta quien las promueve. Las sesiones con una modalidad diádica pueden activar resistencias por parte de los miembros (movimientos homeostáticos), ya que para ellos este tipo de proceso creativo implica desarrollar roles y dinámicas a los que el sistema familiar no está acostumbrado. Por ese motivo, es necesario que se ofrezcan estas propuestas de trabajo una vez que se haya establecido una buena alianza terapéutica y los miembros ya se sientan seguros en su proceso creativo individual, así como en el conjunto.

Cuando las diadas propuestas en la sesión responden al refuerzo de los subsistemas, el proceso creativo en sí mismo resulta un elemento no solo de intervención, 
sino de comunicación intrafamiliar. Por un lado, el subsistema conyugal debe trabajar conjuntamente sobre el mismo soporte, mostrando a sus hijos la capacidad de llevar a cabo proyectos comunes como equipo parental. Por el otro, el trabajo conjunto del subsistema fraternal permite experimentar durante sesión las relaciones propias de este vínculo, pudiendo generarse situaciones en las que se hagan patentes dinámicas habituales entre hermanos como la rivalidad o los celos, así como roles disfuncionales en alguno de los hermanos como la parentalización (llevar a cabo funciones más propias de un padre o de una madre que de un hermano).

La obra, como resultado de este proceso, se convierte en un objeto mediador que permite reflexionar y hablar de los conflictos que se pueden estar dando en la estructura familiar. Además, la experiencia compartida en la sesión permite identificar nuevas estrategias relacionales con las que vivenciar otros modos de identidad familiar durante el juego creativo en la sesión. Por último, desde la contratransferencia estética, el arteterapeuta debe comprender el discurso visual creado por los subsistemas como imágenes que, de una forma metafórica, abren diferentes perspectivas sobre futuras posibilidades respecto al funcionamiento del sistema familiar.

\section{Otros resultados de investigación}

En este trabajo nos hemos centrado en ofrecer una propuesta teórica que ayude a comprender los vínculos que se establecen durante el proceso creativo en Arteterapia Familiar, analizando las relaciones entre los miembros y centrándonos en las funciones de la obra y del arteterapeuta a la hora de intervenir en la dinámica familiar. El desarrollo conceptual aquí expuesto es parte de una investigación en la que también se han obtenido otros resultados de investigación específicos para el trabajo con familias.

A través de dicho estudio se ha desarrollado una técnica de Evaluación Familiar Inicial (EFI) y Evaluación Familiar Final (EFF) en la que ha sido posible detectar algunas variaciones de la dinámica familiar en el desarrollo del proceso creativo compartido (Gutiérrez, 2018). Por otro lado, también se han estudiado algunos elementos del setting que condicionan el proceso creativo de las familias, como la disposición del espacio y de los materiales o la temporalización de las sesiones y del programa arteterapéutico. Otro de los aspectos analizados ha sido la utilidad de las técnicas artísticas en función de los objetivos terapéuticos, logrando identificar qué materiales son más adecuados para promover el trabajo individual, el trabajo conjunto, el desarrollo del lenguaje simbólico, la narrativa, etc. Por último, se ha diseñado un sistema de devolución o cierre centrado en la imagen, en el que la arteterapeuta utiliza el videofeedback para mostrar a las familias el proceso vivido.

\section{Conclusiones}

Como se observa en el planteamiento teórico expuesto, a la hora de trabajar en arteterapia con familias es necesario ser conscientes de la diversidad de vínculos y transacciones que se están dando en una misma sesión. Para poder promover cambios en la dinámica familiar resulta imprescindible una buena construcción del sistema terapéutico, es decir, una acomodación mutua entre familia y arteterapeuta que dé 
lugar a una alianza terapéutica significativa, ya que sin esa relación de confianza no será posible conformar un espacio seguro en el que crear nuevas posibilidades.

Centrándonos en el potencial del proceso creativo como instrumento de intervención terapéutica, es posible comprender cómo a través de la experiencia vivencial en las sesiones los miembros pueden explorar diferentes vías relacionales. En primer lugar, el proceso creativo simultáneo sirve para desarrollar estrategias de autonomía, visibilizando el lugar simbólico que ocupa cada miembro en el sistema, así como sus capacidades y necesidades personales. Por otro lado, el proceso creativo conjunto se convierte en un material de análisis muy útil con el que observar las pautas transaccionales y dimensiones estructurales, haciendo que la familia se muestre de forma espontánea a través del juego compartido en la sesión. Por último, el proceso creativo diádico utilizado como técnica reestructuradora, ayuda a formar unos vínculos más adecuados y a experimentar nuevos modelos relacionales funcionales que se van gestando de forma natural a través del uso del lenguaje verbal, no verbal y visual.

El proceso creativo compartido, así como la obra plástica, son parte fundamental de los movimientos morfogenéticos de la familia ya que permiten un juego de miradas (del arteterapeuta hacia la familia y de los miembros entre sí) con el que poder desarrollar nuevos canales de expresión y de comunicación. Las imágenes generadas en las sesiones de arteterapia familiar se convierten en objetos mediadores que facilitan una apertura al mundo interno de los miembros, y al mismo tiempo son huellas tangibles del proceso terapéutico vivido por la familia. Por ello, resulta indispensable reflexionar acerca de la percepción del profesional sobre las imágenes, comprendiendo que en el trabajo arteterapéutico tanto la observación como la escucha forman parte del desarrollo de los vínculos y de la dinámica familiar.

\section{Referencias bibliográficas}

Corveleyn, J. (1997). Acerca de la contratransferencia ¿obstáculo o instrumento? Revista de Psicología de la PUCP. Vol. 25, nº 2, pp 157-178.

Deco, S. (1990). A family centre: A structural family therapy approach. En Working with Children in Art Therapy, Case, C. y Dalley, T. (Eds). New York: Routledge.

Donelly, M. (2000). Art Therapy with families. En Art Therapy: A handbook. Waller, D. \& Gilroy, A. (Eds). Philadelphia: Open University Press.

Donelly, M. (2013). Some Aspects of art therapy and family therapy. En Pictures at an Exhibition. Selected Essays on art and art therapy. Gilroy, A. \& Dalley, T. (Eds). New York: Routledge.

Goldschmidt, J.(2010) Transferencia, Vínculo Y Alteridad. Congreso Federación Psicoanalítica de América Latina, 23-25 de septiembre. Bogotá, Colombia

Gutiérrez, E (2018). Arteterapia Familiar en Oncología Pediátrica. Psicooncología, vol. 15 (133-151). Doi: 10.5209/PSIC.59183.

Haley, J. (1985). Trastornos de la emancipación juvenil y terapia familiar. Buenos Aires: Amorrortu.

Hervás, L. (2016). Arteterapia para la maternidad y la familia. Introducción al dossier. En Arteterapia. Papeles de arteterapia y educación artística para la inclusión social, vol 11, pp. 127-130. Doi: 10.5209/ARTE.54120

Hoshino, J. (2008) The Development of Family Therapy and Family Art Therapy. En Kerr, C. (coord), Family Art Therapy. Foundations of Theory and Practice (pp. 25-64). Nueva York: Taylor \& Francis Group. 
Im et al. (2010). A KFD web database system with an object-based image retrieval for family art therapy assessments. The Arts in Psychotherapy Vol. 37 (163-171).

Keeney, B. y Ross, J. (1987). Construcción de terapias familiares sistémicas. Buenos Aires: Amorrortu.

Laplanche, J y Pontalis J.B. (2001). Diccionario de Psicoanálisis. Avellaneda, Argentina: Paidós.

Linesch, D. (1993). Art therapy with families in crisis: Overcoming resistance through nonverbal expression. Nueva York: Brunner/Mazel.

Madanes, C. (1984). Terapia familiar estratégica. Buenos Aires: Amorrortu.

Manicom, H.; Boronska, T. (2003). Co-creating change within a child protection system: integrating art therapy with family therapy practice. Journal of Family Therapy, Vol 25, n³, pp. 217-232.

Minuchin, S. (1979). Familias y terapia familiar. Buenos Aires: Gedisa.

Minuchin, S. \& Fishman, H.C. (1984). Técnicas de terapia familiar. Barcelona: Paidós.

Moore, M. Family Art Therapy: A Case Study. (Tesis doctoral). Florida: The Florida State University, 2005.

Moghaddam, K; Zadeh Mohammadi, A; Sharifi, P.; Afrooz G. (2016). Effect of the Familybased Art Therapy Program on the Social Interactions, Verbal Skills and Stereotypic Behaviors of Children with Autism Spectrum Disorders (ASD). Iran J Public Health, Vol. 45, N.6, (830-832)

Riley, S. y Malchiodi, C. A. (2003) Family Art Therapy. En Malchiodi (Ed.) Handbook of Art Therapy (pp 362-374). Nueva York; The Guilford Press.

Schaverien, J. (2000). The Triangular Relationship and the Aesthetic Countertransference in Analytical Art Psycotherapy. En Gilroy, A. y McNeilly, G. (Ed.) The Changing Shape of Art Therapy: New Developments in Theory and Practice (pp. 55-83). Londres, Jessica Kingsley Publishers.

Watzlawick, P., Beavin, J.H., \& Jackson, D.D. (1983). Teoría de la comunicación humana. Barcelona: Herder.

Whitaker, C. \& Bumberry, W.M. (1988). Danzando con la familia. Barcelona: Paidós. 